\title{
The Challenges and Prospects of English in China Under the Belt and Road Initiative
}

\author{
Jinjun Wang ${ }^{1, *}$ Jinyi Huang ${ }^{2}$ \\ ${ }^{1}$ School of Foreign Studies, Guangzhou University, Guangzhou, Guangdong, China \\ ${ }^{2}$ Center for Linguistics and Applied Linguistics, Guangdong University of Foreign Studies, Guangzhou, \\ Guangdong, China \\ *Corresponding author. Email: sfswjj@gzhu.edu.cn
}

\begin{abstract}
Over four decades English has been empowered as the dominant foreign language in China since the Reform and opening-up in 1978. The Belt and Road Initiative (BRI) launched in 2013 has had profound linguistic transformations on China's foreign language policy and has brought observable challenges as well as considerable prospects on English. The paper is intended to justify and evidence the major challenges of English under BRI from the three aspects: (1) China's substantial demand of foreign language resources bringing about an urgent need for enhancing national language capacity; (2) the increasing languages of the countries along the Belt and Road (BR countries) offered in China's universities; (3) English-dominated translation service going together with the escalating BR languages. Besides, the paper underpins the two major future prospects of English, namely, the ongoing trend of improving English proficiency of the Chinese nationals and a heavy demand of competent international talents leading to the imperative reform on English education. It is hoped that the paper is helpful to understand the current status of English and foreign language policy in China.
\end{abstract}

Keywords: English, The Belt \& Road Initiative, Challenges, Prospects, Language policy.

\section{INTRODUCTION}

The Belt and Road Initiative (BRI) proposed by China in 2013, endeavoring to span three continents of Asia, Europe and Africa, and improve regional integration, increase trade and stimulate economic growth, has not only geopolitical and economic implications, but linguistic ones. As a spanning connectivity project, BRI has covered 65 countries with the population of 4.4 billion and at least 53 official languages, including 9 language families and its branches in the world, with over $50 \%$ of the Indo-European languages[18]. Most countries along the Belt and Road (BR countries) are full of palette languages and cultures, albeit English as an official language in many BR countries, such as Singapore, Indonesia, Malaysia, etc.

The late South African President Nelson Mandela once said that, "If you communicate with one another in a foreign language, you are only in his mind; if you communicate with him in his native language, you can go deep into his heart." Obviously, language is a bridge over hearts more than a tool of communication. Due to the linguistic and cultural diversity of BR countries, people-to-people bonds, one of the five priorities of BRI, are thought to be of supreme importance as they reply on efficient communication by means of official languages as well as native languages of BR countries and they provide an anchor to achieve the strategic goal of connecting diverse cultures and countries and promoting economic cooperation.

Admittedly, the implementation of BRI urges a need for quality talents of languages of BR countries and has triggered a series of linguistic transformations nationwide, namely, raising awareness of enhancing national language capacity, giving prominence to BRI-oriented language policies, upgrading translation service industry increasingly shared with more BR languages, etc. All these have inevitable impacts on English, the dominant foreign language since China's reform and opening policy in 1978. For years, Englishdominated foreign language education has been debatable due to the severe imbalance and the 
scantiness of foreign language resources [6][4][10], especially the languages of the BR countries. Undoubtedly, English has encountered observable challenges. Is English not favored in China under BRI? The paper is intended to explore the challenges that English has been facing and its prospects in the future and it is hoped that the paper will shed some light on the better understanding of the status quo of English in China under BRI.

\section{THE CHALLENGES THAT ENGLISH HAS BEEN FACING UNDER BRI}

In the context of BRI, China is striving to enrich its foreign language resources so as to enhance its national language capacity, transforming its national language policy and upgrading translation service to facilitate cultural exchanges, economic growth and global governance. The contextual realities challenge the dominance of English in a tangible way.

\subsection{The Substantial Demand of Foreign Language Resources Brings an Urgent Need for Enhancing National Language Capacity}

For recent years English-dominated foreign language education has been in controversy as the supremacy of English has resulted in the imbalance of the foreign language resources and restrained the development of other foreign languages [6] [5] [10]. According to Zhong \& Sun [24], among 1,145 universities in China, 994 (86.8\%) have Bachelor program for the English language, an increase of 95 compared with the data provided by Dai Weidong [4]. The same situation is found in China's vocational colleges. 1144 of 1168 (97.9\%) vocational colleges nationwide have proffered English courses for Bachelor program [11] in other words, almost every college has its English program. Contrary to the rapid growth of English, languages other than English, usually called less commonly taught languages have been overshadowed and remain sluggish as regards the student enrollment, the program levels and the number of universities that can offer lesscommonly-taught language courses, etc.

The discordance of foreign language resources is notably acknowledged and is typically exemplified by the proportion of learners between English and non-English languages. Among 416 million foreign-language learners in China, $93.80 \%$ learned English as the only foreign language, 7.07\% Russian, Arabic 0.13\%, Spanish 0.05\%, French $0.29 \%[21]$. The data showcase the unbalanced proportion between English and nonEnglish languages. In fact, the lopsided foreign language resources with the dearth of BR languages, are far from meeting the needs of BRI implementation. A proposal of enriching foreign language resources and enhancing national language capacity has been advocated [10][23] and consequently was included in the '13th Five-Year Plan' for National Languages ('13th Five-Year Plan' in brief), a national-level guiding document.

Although the term "national language capacity" was first put forward by American scholars to reflect American interest of maintaining national security by improving its foreign language capacity after September 11th terrorist attacks[2], it has been endowed with new connotations in the context of BRI. As "the BRI represents a profound transformation of national interest strategy and is an essential step in China's increased proactive participation in regional and global governance and development" [8] national language capacity, taken to be soft power and hard power, concerning national economic development, scientific innovation, national administration and international competitiveness, pertains to a nation's capability of owning resources of national languages and foreign languages, providing language services and effective linguistic administration, and dealing with linguistic issues nationwide and even overseas when China's interest is concerned[10][23][20][22]. In fact, national language capacity is a matter of national security and national interest. Indubitably, foreign language resources and foreign language capacity are indispensable components for implementing BRI.

The '13th Five-Year Plan', a directive document, promulgated by the Ministry of Education (MOE) and National Language Commission in August 2016, officially specifies national language capacity at the first time and clearly states that China's national language capacity should adapt to its comprehensive national strength. In the Plan, the concept of language as resources[13] is stressed formally and language resources as crucial cultural, economic and strategic resources, are further pinpointed. More effort is demanded in the Plan to pay to the research on BR languages, the survey on talent reserves of foreign and national languages, and the establishment of 
BR language resource bank for the benefit of national grand strategy and development.

Ruíz[13] proposes three orientations of language planning in practice, that is, language-asa-problem, language-as-a-right and language-as-aresource. China's language planning has gone through the first two and is experiencing the third. In the 1950's and 1960's, China has undertaken two modes of language planning as most countries have done, that is, language-as-a-problem, which can be shown in China's implementation of simplified Chinese written characters and Pinyin systems after the founding of the People's Republic of China and language-as-a-right, which is witnessed by legalizing the rights of using mother language among all ethnic minorities. With China's peaceful rise, the improvement of comprehensive national strength and the global leadership facilitates language policy makers and administrators to accentuate the concept of language-as-a-resource. Accordingly, the English-dominated foreign language policy has been transformed timely to meet the needs of the implementation of BRI.

\subsection{The Increasing BR Languages Offered in China's Universities}

In order to give impetus to BRI, MOE has taken a series of measures of orienting to the mastery of BR languages, including the approval of more universities to offer BR language courses; the enhancement of BR languages in tertiary education and the cultivation of quality talents, etc.

The document entitled "The Implementation Guidelines of MOE on Strengthening the Cultivation of Talents of Less Commonly Taught Languages" was officially released in September 2015, in which the development of BR languages was further stressed out of respect for national language capacity and national strategy. In 2016, another directive issued by MOE, "Advancing the Joint Construction of the Belt and Road Education Action" clearly underscores the importance of multilingual communication and the cultivation of foreign language talents. Since 2015, universities of foreign studies and comprehensive universities across the country have made effort to offer BR language courses in the blowout way [14].

As of 2018, 268 universities and 52 junior colleges offered BR language courses, totalling 65 postgraduate programs and 20 doctoral programs of BR languages nationwide [19]. Besides, the student enrollment of BR languages reached 108,800, inclusive of 25,299 junior college students, 78,197 undergraduates, 4,951 graduates and 359 doctoral candidates [19]. As BRI is in progress, universities and colleges with BR language courses have been burgeoning. We made a survey on the numbers of foreign languages and BR languages taught in China's universities in 2019, and universities offering over 10 BR language courses are illustrated in "Table 1".

Table 1. China's Universities Offering over 10 BR Language Courses

\begin{tabular}{l|l|l|l}
\hline Rank & \multicolumn{1}{|c|}{ Name of University } & No. of Foreign languages & No. of BR Languages \\
\hline 1 & Beijing Foreign Studies University & 98 & 50 \\
\hline 2 & The PLA Information Engineering University & 33 & 25 \\
\hline 3 & Tianjin Foreign Studies University & 32 & 23 \\
\hline 4 & Beijing International Studies University & 26 & 21 \\
\hline 5 & Shanghai International Studies University & 27 & 18 \\
\hline 6 & Guangdong University of Foreign Studies & 26 & 16 \\
\hline 7 & Yunnan University for Nationalities & 16 & 15 \\
\hline 8 & Peking University & 20 & 14 \\
\hline 9 & Xian International Studies University & 18 & 12 \\
\hline 10 & Communication University of China & 21 & 11 \\
\hline 11 & Sichuan International Studies University & 16 & 10 \\
\hline
\end{tabular}

As can be seen from "Table 1", as of 2019, there were 11 universities offering over 10 BR official languages, including English, 3 universities more than 20 BR languages, remaining 7 over 10 languages. Our survey reveals that most universities in China have set up three to five BR languages. Beijing Foreign Studies University is leading far ahead with offering $50 \mathrm{BR}$ languages. Despite of the failure to offer three BR languages, that is, Dzongkha, Montenegrin and Moldovan, the University has covered all the other BR languages and ranks first. 
However, the acute shortage of BR language talents is still very noticeable, that is, some BR languages are only accessible in a few colleges and universities. Nearly 20 languages such as Dhivehi and Tetum are only taught at Beijing Foreign Studies University and some languages are only taught in a few universities, such as Albanian, Estonian, Bulgarian, Bosnian, Czech, Croatian, etc.

\subsection{English-dominated Translation Service Shared with the Escalating $B R$ Languages}

Translation industry as a traditional language service industry grows and accelerates with China's pace of reform and opening up and has been further boosted under the context of BRI. According to 2018 China Language Service Industry Development Report (2018 Report)[16], there were 249 colleges and universities with Master program of Translation and Interpretation (MTI), and 272 with Bachelor program of Translation and Interpretation(BTI), involving the languages of English, French, Japanese, Russian, German, Korean, Spanish, Arabic and Thai. One year later, in 2019 China Language Service Industry Development Report (2019 Report)[17], 4 more universities enabled to own MTI program and 9 more to confer BTI . The language coverage of MTI and BTI has increased from 9 in 2018 to 11 in 2019, and Italian and Vietnamese were new members.

The 2018 Report [16] illustrates that English, French, Japanese, German, and Russian are the top five languages for translation service in China. Specifically speaking, in the Chinese-foreign language translation activities, several major languages by the service suppliers involve English (97.8\%), which takes the lead; Japanese (69.9\%) and French $(69.7 \%)$ as the second place; German (59.2\%), Korean (54.2\%) and Russian $(45.5 \%)$ as the third; and Spanish (38.8\%), Portuguese (34.6\%) and Arabic (27.1\%) to be the fourth. In accordance with 2019 Report [17], translation service providers have an urgent need of language talents of Italian, Arabic, Portuguese, Spanish and Thai; whereas the demand sides need badly the talents of Russian, Arabic, German and French, especially some BR languages, namely Vietnamese, Belarusian, Polish and Mongolian. Three BR languages, that is, Montenegrin, Slovak and Turkmen are extremely needed in the near future.

Despite the paramountcy of English in translation service, the rapid growth of $\mathrm{BR}$ languages has been witnessed to take their own shares. The increase of $\mathrm{BR}$ languages is also noticeable in high-profile international events hosted by China in recent years. At the 11th Summit of the Group of Twenty (G20) leaders held in Hangzhou in September, 2016, the Summit News Center provided 24-hour online translation services for nearly 5,000 Chinese and foreign reporters from 70 countries and regions by using 8 multi-lingual telephones in 14 languages including English, Russian, French, Indonesian, Portuguese, Arabic, etc. Besides, multilingual Emergency Services Platform "96020" had worked efficiently owing to 248 experienced interpreters in 14 languages.

\section{THE FUTURE PROSPECTS OF ENGLISH IN CHINA}

English in China is just like the eldest child in a family. With the increase of the siblings, his favor is shared and partitioned to a certain degree, but his role as a leader and an exemplar remains unchanged. In the context of BRI, English has been still the most frequently used language and its status as an international lingua franca is unshakable. Park \& Wee[12] point out that English is valued over other languages in the hierarchical structure of the linguistic market as "neoliberal commodification transforms language into an acquirable skill"[12:189]. Furthermore, the instrumental and pragmatic attractions of English are much greater than those of other languages [1] and English proficiency has become incomparable in the job market.

With the ongoing trend of improving English proficiency in China, it is optimistically estimated that the trend will turn out to be a great demand of competent international talents due to China's positively integrating international competition, proactively participating global governance and jointly building a community of common destiny for all mankind, and therefore it likely forces English education to transform substantially and dramatically.

\subsection{The Ongoing Trend of Improving English Proficiency of the Chinese People}

China has the largest population of English learners in the world. English learners took up $93.8 \%$ [21] and over 390 million population are of English proficiency at different degrees. $E F$ Education, the world's largest private education 
company, has created five levels for the EF English Proficiency Index(EPI), namely, very high, high, moderate, low and very low, to measure English communication skills of adults, regarding speaking proficiency level of the citizens of countries where English is not an official language ${ }^{1}$. According to EF Education survey, Chinese English proficiency has been unsatisfactorily low from 2011 to 2018 . However, 2019 witnessed a historical breakthrough that China's EF EPI has risen from low to moderate proficiency by ranking 40th among 100 countries and $8^{\text {th }}$ of 25 Asian countries, scoring 53.44 with an increase of 1.5 more than in 2018.

Likewise, the statistical analysis of IELTS test taker performance in mainland China has also indicated the increase of English proficiency of Chinese test takers. According to 2018 White Paper on China's IELTS Test Taker Performance (concerning Academic and General Training), from 2012-2017 an outstanding progress is observed in English proficiency of two types of test takers that 5.5 and 6.0 are two typical overall band scores for Chinese test takers and half of the test takers have got 6.0. Specifically, general training test takers have better performance in listening and reading, but weaker in writing and speaking. The average writing band score increased from 5.24 in 2012 to 5.39 in 2017. The academic test takers have had remarkable improvement on listening and writing and their best performance is found in reading with the average of 6.0. Speaking, is comparatively weak for all the test takers of two types. "Table 2" shows the improvement of academic test takers in 2012, 2016 and 2017.

Table 2. Average Performance of IELTS Academic Test Takers in 2012, 2016 and 2017

\begin{tabular}{l|l|l|l|l|l}
\hline Year & $\begin{array}{c}\text { Average } \\
\text { overall band } \\
\text { score }\end{array}$ & Listening & Reading & Writing & Speaking \\
\hline 2017 & 5.76 & 5.9 & 6.11 & 5.37 & 5.39 \\
\hline & $+0.12 \uparrow$ & $+0.11 \uparrow$ & $+0.1 \uparrow$ & $+0.13 \uparrow$ & $+0.11 \uparrow$ \\
\hline 2016 & 5.64 & 5.79 & 6.01 & 5.24 & 5.28 \\
\hline & $+0.08 \uparrow$ & $+0.12 \uparrow$ & $+0.11 \uparrow$ & $+0.08 \uparrow$ & $+0.03 \uparrow$ \\
\hline 2012 & 5.56 & 5.67 & 5.9 & 5.16 & 5.25 \\
\hline
\end{tabular}

1. Countries That Are Most and Least Proficient in English, https://www.worldatlas.com/articles/countries-that -aremost-and-least-proficient-in-english.html, 2020-06-20.

\subsection{A Heavy Demand of Competent International Talents Leading to the Imperative Reform on English Education}

Despite of the improved English proficiency in China, there is a strong demand of high-quality international talents featuring higher English proficiency. $\mathrm{Hu}$ [7] claims that high-quality talents are seriously insufficient disregarding a surplus of general-level graduates. Zhang[25] points out that English majors are cultivated with the homogenized model of grasping English language skills plus knowledge of humanities and social sciences, which has resulted in the narrowed job markets and the long-term oversupply of graduates.

Indeed, the overall improvement of English proficiency in China leads to a higher expectation on English education at different levels. At the university level, the possible reforms of English teaching for English majors and non-English majors have been under discussion for years. The aim of cultivating competent international talents is highlighted after the scrutiny of the different opinions, including popularizing English for Specific Purposes (ESP) teaching model for nonEnglish majors [3]; or developing compound talents of foreign languages[8] or cultivating multilingual talents subsuming English plus less commonly taught languages[26] and less commonly taught languages plus English [15].

In order to cultivate competent international talents, Jiang \& Xie[9] stressed the characterized English education in different types of universities. They hold that universities of foreign studies should be committed to the cultivation of high-potential foreign language talents, focusing on their capability of multilingualism and translation, and their ability to participate in international relations, foreign affairs, etc. For normal universities, foreign language teaching methods and practices should be accentuated while striving to train high-quality English teachers. Universities of finance and economics should focus on training business English talents, emphasizing their ability to combine the English language with business activities. For the comprehensive universities, English language teaching should give prominence to the regional characteristics, or the advantages of the universities themselves.

The characterized English education resonates to the cultivation of compound talents of foreign languages. "Compound talents" per se has been 
possibly interpreted as the students with professional knowledge and skills in juxtaposition to high English proficiency[14][8]. The students should be acknowledged with the expertise knowledge in specific fields such as business, finance, law, economics, science, etc, which can be regarded as the fields with high demand of English talents. The high-level specialized expertise with good English proficiency can be conducive to compete in an international arena. In addition, the multilingual compound talents tend to be English majors, who choose another foreign language rather than English to learn or the majors of less commonly taught languages, who endeavor to improve their English proficiency, for the sake of possessing multilingual competency to serve the implementation of BRI. Thus the cultivation of the multilingual compound talents can efficiently realize the transition from having only English proficiency to multilingual competency.

\section{CONCLUSION}

English as a dominant foreign language in China is steadfast, and it will go hand in hand with other foreign languages, especially BR languages. In order to implement successfully BRI, national foreign language resources and foreign language capability are further pinpointed and underscored, bringing forth the strong demand of the competent international talents with high-level English proficiency. Definitely, there is a great expectation on English educators and educational institutions and much work should be done as English has an irreplaceable role to play in China under BRI.

\section{AUTHORS' CONTRIBUTIONS}

Jinjun Wang contributed to the paper writing, revising and editing, and Jingyi Huang was responsible for the data collection and analysis.

\section{REFERENCES}

[1] Bolton, K. \& Graddol, D. 2012. 'English in China today'. English Today, 28(3): 3-9.

[2] Brecht, R. \& Walton, A.R. 1993. (ED367184). 'National strategic planning in the less commonly taught languages'. NLFLC Occasional paper.

[3] Cai, J. 2004. 'ESP yu woguo daxue yingyu jiaoxue fazhan fangxiang'[ESP and the directions of College English teaching in
China]. Yaiyujie [Foreign Language World], (2) :22-28.

[4] Dai, W. 2009. 'Woguo waiyu zhuanye jiaoyu 60 nian: huigu yu zhanwang' [Review and Prospect of 60-year Foreign Language Education in China. Zhongguo Waiyu[ Foreign Languages in China], (5):10-15.

[5] Dai, W. \& Wu, F. 2010. 'Woguo waiyu xueke fazhan de yueshu yu duice'[On the development of foreign language studies in China: Constraints and strategies]. Waiyu Jiaoxue $Y u$ Yanjiu[Foreign Language Teaching and Research], (3):170 - 175+240.

[6] Hu, W. 2001. 'Woguo waiyu jiaoyu guihua de de yu shi' [A matter of balance - Reflections on China' $\mathrm{s}$ foreign language policy in education]. Waiyu Jiaoxue уи Yanjiu[Foreign Language Teaching and Research], (4): 245251.

[7] Hu, W. 2014. 'Shilun woguo yingyu zhuanye rencai de peiyang: huigu yu zhanwang'[On the training of English majors in China: retrospect and Prospect'], Waiyu Jiaoxue Yu Yanjiu[Foreign Language Teaching and Research], 46(1): 111-117.

[8] Huang, L. 2019. 'Development of Foreign Language Education in China under the Belt and Road Initiative'. Journal of Language and Education, 5 ( 4 ): 138-145.

[9] Jiang, H. \& Xie, M. 2017. 'Guanyu qicao gaodeng xuexiao yingyu zhuanye jiaoxue dagang(xinban) de jidian sikao'[Reflections on formulating the new national syllabus for college English majors]. Waiguo Yuyan $\mathrm{Yu}$ Wenhua[Foreign Languages and Cultures], 1(1): 1-10.

[10] Li, Y. 2010. 'Zhongguo waiyu guihua de ruogan sikao'[Some Thoughts on Foreign Language Planning in China. Waiguoyu[Journal of Foreign Languages], (1): 2-8.

[11] Liu, D. \& Zhang, J. 2009. 'Gaozhi gaozhuan gongong yingyu jiaoxue xianzhuang diaocha yu gaige silu'[The Current Teaching Situations and Reforms in General English Teaching in Vocational Higher Education: Analysis and Prospects [J]. Zhongguo Waiyu [Foreign Languages in China], (6): 77-83. 
[12] Park, J. S. Y. \& Wee, L. 2012. Markets of English: Linguistic Capital and Language Policy in a Globalizing World. New York: Routledge.

[13] Ruíz, R. 1983. 'Orientations in language planning'. Bilingual Research Journal, 8(2), $15-34$.

[14] Shen, Q. 2019. 'Xinzhongguo waiyu jiaoyu guihua 70 nian:fanshi bianqian yu zhanlue zhuanxing'[70 Years of Foreign Language Education Planning of China: Paradigm Changes and Strategic Shifts]. Xinjiang Shifan Daxue Xuebao(zhexue shehui kexue ban)Journal of Xinjiang Normal University(Philosophy and Social Sciences),40(5):68-77.

[15] Su, Y. 2017. 'Yidai yilu feitongyongyu rencai peiyang moshi de sikao yu tansuo' [Thinking and exploration on the talent training mode of less commonly taught languages of the Belt and Road], Zhongguo Waiyu Jiaoyu[Foreign Language Education in China], 10(2): 3$7+95$.

[16] Zhongguo Fanyi Xiehui [Translators Association of China]. 2018. 2018 Zhongguo Yuyan Fuwu Hangye Fazhan Baogao[2018 China Language Service Industry Development Report]. Beijing: Foreign Languages Press.

[17] Zhongguo Fanyi Xiehui [Translators Association of China]. 2019. 2019 Zhongguo Yuyan Fuwu Hangye Fazhan Baogao[2019 China Language Service Industry Development Report]. Beijing: Foreign Languages Press.

[18] Wang, H. \& Wang, Y. 2016. 'Yidai yilu' yanxian guojia yuyan zhuangkuang' [Language situation of 'the Belt and Road' countries]. Yuyan Zhanlue Yanjiu [Chinese Journal of Language Policy and Planning], 2, 13-19.

[19] Wang, H. \& Xia, J. 2019. "Yidai yilu' feitongyongyu rencai peiyang yu shichang xuqiu diaocha'[The less commonly taught languages of the "Belt and Road"countries in Chinese higher education institutions: a survey of the talent cultivation and the market demand]. Waiyu Dianhua Jiaoxue[TEFLE], (1): 30-36.
[20] Wei. H. 2015. 'Guojia yuyan nengli youguan wenti tantao'[On some aspects of national language competence].Yuyan Wenzi Yingyong[Applied Linguistics], (4): 35- 43.

[21] Wei, R. \& Su, J. 2012. 'The statistics of English in China'. English Today, 28( 3):1014.

[22] Wen, Q. 2016. 'Guojia yuyan nengli de neihan jiqi pingjia zhibiao'[Defining national language capacity and identifying its evaluation indicator. Yunnan Shifan Daxue Xuebao(zhexue shehuikexue ban)[Journal of Yunnan Normal University (Philosophy and Social Sciences)], (2): 23- 30.

[23] Zhao, S. 2015. 'Quanqiu jingzheng zhong de guojia yuyan nengli'[National Language Capacity in Global Competition]. Zhongguo Shehui Kexue[Social Sciences in China], (3): 105- 118.

[24] Zhong, M. \& Sun, Y. 2014. 'Yi rencai peiyang wei zhongxin,quanmian tuijin waiyulei zhuanye jiaoxue gaige yu fazhan'[Advancing the teaching reforms and development of foreign language majors based on talent cultivation. Waiyu Jie [Foreign Language World], (1):2-8.

[25] Zhang, B. 2007. 'Jintian, women xuyao shenmeyang de waiyu rencai?'[What language talents do we need today?]Guangming Ribao[Guangming Daily], 2007-03-01.

[26] Zheng, Y. 2020. 'Zonghexing daxue waiyu zhuanye fuyu rencai peiyang tansuo: yi fudan daxue yingxiyu shuangyu moshi weili'[Exploring dual-foreign-language education in comprehensive universities: Fudan University's innovation]. Wаiуи Јiaoyu Yanjiu Qianyan[Foreign Language Education in China], 3(1): 8-14. 